Recebido: 15/12/2016

Aprovado: 01/02/2017

\title{
Desigualdade social e narcotráfico na América Latina: Colômbia em foco (1999-2012)
}

\author{
Lucas Querino de Carvalho Moraes*
}

\begin{abstract}
Resumo: Com o objetivo de manter a permanência de sua liderança política, econômica e militar, além do status de única superpotência mundial no Pós-Guerra Fria, os Estados Unidos viram-se na obrigação de conter as ameaças que os países latino-americanos representavam aos seus interesses, entre elas, $o$ narcotráfico. Adotando uma política de combate às drogas, que se materializou na "guerra de baixa intensidade", os EUA colocaram em prática o Plano Colômbia, dando início a uma série de ataques violentos e a dizimação de populações de camponeses e plantações de coca, ferindo assim os direitos humanos e acentuando ainda mais o narcotráfico e a migração ilegal. O objetivo deste artigo é mostrar que a desigualdade social ainda é um forte problema na América Latina, e que, aliada a outros fatores, configura-se como uma das grandes responsáveis pela atividade do narcotráfico na região. Além disso, pretende-se expor caminhos para o combate a essa desigualdade em países como a Colômbia, tais como a criação de políticas públicas e sociais.
\end{abstract}

Palavras-chave: Desigualdade social; narcotráfico; Plano Colômbia.

Abstract: Aiming the permanence of their political, economic and military leadership, beyond the world's only superpower status in the Post-Cold War, the United States saw itself forced to contain threats that Latin American countries represented to their interests, including the drug trafficking. Adopting an anti-drug policy that materialized in a "low-intensity war", the US put into practice the Plan Colombia, beginning a series of violent attacks and decimation of the peasants populations and coca plantations, wounding so, human rights and further accentuating even more the illegal migration and drug trafficking. The purpose of this article is to show that the social inequality still is one of the biggest problems in Latin America, and allied to other factors its commonly responsible for the drug trafficking activity in the region. In addition, we intend to expose possible ways to combat this inequality in countries such as Colombia and Bolivia, as per the creation of public policies.

Keywords: Social inequality; drug trafficking; Plan Colombia.

\footnotetext{
* Graduando em História na Universidade de Brasília
} 
O uso e o combate às drogas sempre estiveram presentes na história. Na década de 1960, por exemplo, a Contracultura, principalmente nos Estados Unidos, além de ter sido um importante movimento social, cultural e político, caracterizou-se também pelo uso do $\mathrm{LSD}^{1} \mathrm{e}$ personalidades da música como Bob Marley e Eric Clapton assumiram abertamente o consumo de substâncias alucinógenas e entorpecentes. Na década de 1980, o colombiano Pablo Escobar desenvolveu o seu comércio de venda de cocaína, tornando-se o maior contrabandista da droga para os Estados Unidos e outros países e o narcotraficante mais procurado no mundo.

Em 1971, os Estados Unidos, sob o governo de Richard Nixon (1969-1974), começaram movimentações de combate às drogas no seu âmbito interno e o então presidente propôs uma revisão de todo o código penal federal com a inclusão de punições mais severas com relação às drogas e ao crime.

Em 1980, o presidente Ronald Reagan declarou que a maconha era a droga mais perigosa dos Estados Unidos, e, ao final da mesma década, no Pós-Guerra Fria, foi lançada uma política de segurança para a América Latina a fim de conter as ameaças que a região representava aos interesses norte-americanos, tais como o tráfico de drogas, as migrações ilegais e os regimes democráticos, visto que a instabilidade política da região ameaçava diretamente a promoção e o fortalecimento da democracia liberal e das economias de mercado, objetivos centrais da política externa dos EUA para a América Latina.

A Colômbia, país com a maior produção mundial de cocaína e com quantidade considerável de plantações de $\operatorname{coca}^{2}$, rapidamente tornou-se um alvo norte-americano. $\mathrm{O}$ resultado dessa política de segurança foi uma "guerra de baixa intensidade" que, além de ter desrespeitado fortemente os direitos humanos, não conteve efetivamente a produção de drogas e o narcotráfico, pelo contrário, os acentuou. Os principais atingidos por essa política na Colômbia foram grupos socialmente desiguais e em condições econômicas precárias: os cocaleiros.

Utilizou-se neste artigo uma base historiográfica recente, dados históricos e estatísticos, análise econômico-social e informações de relatórios internacionais (fontes primárias) para expor que a razão desse problema foi e continua sendo a grande desigualdade

\footnotetext{
${ }^{1}$ LSD é a sigla em inglês para dietilamida do ácido lisérgico, uma das mais potentes substâncias alucinógenas conhecidas e manipuladas em laboratório.

${ }^{2}$ A coca (Erythroxylum coca) é uma planta de tradição milenar nativa da Bolívia e do Peru, tem porte arbustivo/arbóreo e também é utilizada na produção de cocaína. Possui benefícios para o organismo humano como a formação de células musculares, prevenção de úlceras e gastrite, além de impedir o mal estar proveniente de grandes altitudes. Os produtores de coca são conhecidos como cocaleiros.
} 
social ainda presente em todos os países da América Latina. Este trabalho contribui para o entendimento da histórica relação entre desigualdade social e narcotráfico, buscando tratar esses problemas como uma preocupação coletiva que não será resolvida por meio de políticas repressivas ou qualquer outro tipo de medidas violentas e desumanas. Essa não é a solução para o problema, nem do ponto de vista econômico, político e muito menos social.

\section{Estados Unidos e América Latina: o Pós-Guerra Fria}

As relações entre os EUA e a América Latina nos primeiros anos posteriores ao final da Guerra Fria, no início da década de 1990, mudaram significativamente e foram caracterizadas por uma reformulação na política de segurança norte-americana para a América Latina. Com a desintegração da União das Repúblicas Socialistas Soviéticas (URSS), até então a maior inimiga ideológica, política e militar dos EUA, as atenções norte-americanas voltaram-se para novos atores do cenário mundial, os países latino-americanos, reconhecendo-se, na região, uma série de ameaças à manutenção da segurança e à integridade de única superpotência mundial. Ao estabelecerem essas novas ameaças, foram identificadas, pelos Estados Unidos, várias preocupações relacionadas à "debilidade das instituições democráticas, a produção de armamentos e destruição em massa, ao papel das organizações regionais de segurança, às insurgências armadas e à emigração clandestina" (SANTOS, 2007:175). Nesse sentido, a difusão das reformas neoliberais e dos acordos de liberalização comercial foram alguns dos principais objetivos dos Estados Unidos para a América Latina. Contudo, segundo Monica Herz (HERZ, 2002) é possível perceber ainda uma forte tendência à expansão da agenda de segurança norte-americana, com a inclusão de temas como a política de migração, a proteção das fronteiras, as disputas territoriais, o terrorismo, os desastres ambientais e o tráfico de drogas, pois essas questões afetavam diretamente a liderança política e militar dos Estados Unidos.

Segundo Moniz Bandeira, com o fim da Guerra Fria, os Estados Unidos precisavam de uma justificativa para manter e expandir sua vasta estrutura militar, construída desde 1947 com o objetivo de conter o avanço da União Soviética e do "comunismo internacional", por meio de alianças com outros países e de altos gastos em defesa, tendo destinado, por exemplo, US\$ 11,5 trilhões à sustentação da máquina de guerra americana, assistência militar a outros países, atividades de inteligência, coleta de informações, preparação de defesa civil e pesquisa militar (BANDEIRA, 2005:482). 
Além de expor tais informações, Bandeira alerta, ainda que superficialmente, para o fato de que o combate às drogas tornou-se uma questão relevante na agenda interna dos Estados Unidos, não só por representar uma ameaça aos seus interesses político-econômicos, mas também a fim de não perder tais investimentos em segurança. Entretanto, vale salientar que o narcotráfico sempre foi uma preocupação dos Estados Unidos, pois ao se analisar o processo histórico de formação e consolidação da nação norte-americana, evidencia-se a combinação de uma moral puritana com uma ética protestante e individualista de dedicação ao trabalho, criando-se assim um ambiente social de forte repressão ao vício e à dependência química e psicológica (SANTOS, 2007:176). Bem como afirma Marcelo Santos, "nesse país, as leis contra o ópio, o álcool, a maconha, a heroína, a morfina e a cocaína decorreram de intensas pressões de movimentos puritanos, que levaram o Estado a criminalizar os produtores, os vendedores e os consumidores desses produtos" (SANTOS, 2007:176). Desde então, os Estados Unidos passaram a adotar uma legislação proibitiva e repressiva, que marginalizou diversos segmentos da população e deu abertura à formação e ao desenvolvimento de economias ilegais e criminosas.

A prática dessa política não se restringiu ao âmbito interno dos Estados Unidos, ao passo que foram se destacando e ganhando influência no sistema internacional ao decorrer do século XX, buscaram expandir globalmente o seu modelo repressor de combate às drogas. Com a criminalização do comércio e do consumo, os EUA viram a necessidade de combater o narcotráfico interno e externo nos países que ainda permitiam e/ou não tinham controle sobre essa atividade. Sendo assim, os norte-americanos passaram a pressionar os países produtores de substâncias alucinógenas e entorpecentes a seguirem uma política antidrogas semelhante à dos EUA, internacionalizando-a, com a finalidade de defender seus objetivos diplomáticos e comerciais, tanto é que, por muitas vezes, o tema do narcotráfico foi associado à criminalidade, ao comunismo e até mesmo ao terrorismo (SANTOS, 2007:177).

Com a influência norte-americana intensificando-se no cenário mundial, o seu modelo de política antidrogas universalizou-se e transformou-se em legislação internacional. A Convenção sobre Substâncias Psicotrópicas, promovida nos Estados Unidos em 1971, contou com a participação de 71 países, inclusive latino-americanos, tais como Argentina, Brasil, Chile e Colômbia, estabeleceu um sistema de controle internacional para substâncias psicotrópicas, criou formas de controle sobre diversas drogas sintéticas e foi um passo importante no processo de combate às drogas. Em 1973, foi criado, nos EUA, o Órgão de Controle e Combate às Drogas, que acumulou funções de cuidar da política antidrogas dentro

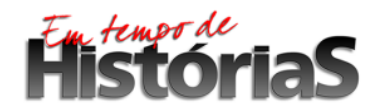


do próprio país e das ações contra o narcotráfico no exterior (TENA, 2000). Ao decorrer do processo de influência internacional e de luta contra as drogas, sob o governo do presidente Ronald Reagan (1981-1989), a América Latina despertou cada vez mais a atenção dos EUA, tornando-se alvo de críticas e sendo altamente responsabilizada pelo consumo de drogas naquele país, falou-se em um "narcoterrorismo"3 e uma "conspiração de latinos", que seria formada por grupos comunistas que confabulavam contra a saúde, a higiene, a moral, aos valores, a segurança e ao poder norte-americano (SANTOS, 2007:178).

Sendo assim, a política externa de Reagan começou a pressionar determinados países latino-americanos com a intenção de erradicar os plantios de ervas e reprimir o narcotráfico. Contudo, além de pressões de cunho político, econômico e diplomático, incluindo até ameaças do uso da força, o governo norte-americano estabeleceu a Certificação, uma ferramenta de monitoramento e avaliação dos esforços antinarcóticos dos países da América Latina, suspendendo a assistência econômica, impondo sanções comerciais e vetando empréstimos de organismos internacionais de crédito aos países que não estivessem de acordo com as suas diretrizes (SANTOS, 2007:179). A estratégia de Reagan ao combate às drogas falhou, pois "não contemplava a resolução de problemas que levavam à expansão do narcotráfico na região, tais como a crise econômica, a pobreza no campo, a debilidade internacional, a desintegração territorial e a violência" (TENA, 2000).

O governo de George H. W. Bush (1989-1993) deu continuidade à política antidrogas norte-americana e retomou o conceito de "guerra às drogas", porém intensificou-se e caracterizou-se por uma série de ações mediante a intervenção militar, entre elas, a Operação Causa Justa, ocorrida em 1989, que contou com a maior mobilização de tropas no exterior desde a Guerra do Vietnã (cerca de 25 mil soldados), para intervir no Panamá. "O objetivo foi testar, em um cenário contemporâneo, o planejamento e a execução conjunta de operações de contingência em países menos desenvolvidos" (BANDEIRA, 2005:484). A operação resultou na morte de dezenas de militares americanos e soldados panamenhos.

Ações como essa, de forte intervenção militar, causaram desconfiança em diversos países latino-americanos, até que em 1990, na Cúpula de Cartagena, os EUA propuseram a criação de uma força militar multilateral de combate ao narcotráfico. A proposta foi recusada pela maior parte dos países da América Latina, principalmente os sul-americanos. Perante a recusa desses países às estratégias de intervenção militar e multilateral, os EUA passaram a

\footnotetext{
${ }^{3}$ Nesse contexto, o governo dos EUA buscou associar cada vez mais o narcotráfico à atividade proveniente de grupos terroristas, com a finalidade de justificar seu envolvimento mais direto e efetivo na luta contra as drogas.
} 
concentrar suas forças em um novo método de combate: a "guerra de baixa intensidade", que se concretizou mediante a prática de diversas medidas, entre elas, o Plano Colômbia.

"Guerra de Baixa Intensidade": o Plano Colômbia

A "guerra de baixa intensidade", do ponto de vista conceitual, já é algo problemático. É complicado pensar em uma guerra, seja ela motivada por razões políticas, econômicas ou militares, sendo menos tensa e pouco devastadora. Muitos dos conflitos considerados de baixa intensidade até hoje, tiveram um saldo extremamente negativo e consequências trágicas. É o caso da Guerra Eritreia-Etiópia, ocorrida em 1998, em que se estima a morte de 50 a 300 mil pessoas, e a Guerra do Chaco, ocorrida em 1932 entre Bolívia e Paraguai, que deixou um saldo de 60 mil bolivianos e 30 mil paraguaios mortos. Barroso afirma que "a baixa intensidade engloba o conjunto das operações militares cuja finalidade está para aquém da destruição de forças militares" (BARROSO, 2009). Nesse mesmo sentido, o historiador brasileiro Carlos Azambuja (AZAMBUJA, 2015), define o conflito de baixa intensidade como uma luta político-militar em que a conexão entre o político e o militar é tão forte que a distinção entre os dois torna-se difícil, além disso, um dos motivos que pode levar a conflitos como esse é o combate ao crime organizado, seja qual for o seu caráter.

Justamente com a intenção de conter esse tipo de crime, combatendo o narcotráfico, principalmente na região andina, onde se concentra a maior produção de drogas do mundo, os Estados Unidos promoveram e investiram altamente na estratégia da "guerra de baixa intensidade", em que ofereceram recursos econômicos e militares para que os países latinoamericanos pudessem implementar ações e combates internos. Uma das prioridades dessa política, fundamentada na criminalização dos produtores, consumidores e traficantes, na erradicação dos cultivos e no combate ao tráfico de drogas, foi a Colômbia.

Diversos foram os motivos pelos quais a Colômbia tornou-se um alvo prioritário dos Estados Unidos e de sua política antinarcótica. Antes de mencioná-los, é preciso uma breve contextualização acerca da economia colombiana.

Ao final da Segunda Guerra Mundial, a Colômbia, diferenciando-se do histórico dos demais países latino-americanos, apresentou uma estabilidade econômica. Segundo Vidigal, “entre 1945 e 1985, o país cresceu a taxa média de 4,8\% e consolidou o desenvolvimento capitalista que havia iniciado nas primeiras décadas do século XX” (VIDIGAL, 2004:172). Esse avanço caracterizou-se pelo crescimento de novas atividades econômicas, destacando-se

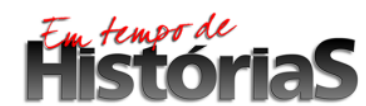


a indústria manufatureira, em detrimento das produções no setor agropecuário ${ }^{4}$. Entre os resultados desse desenvolvimento econômico, encontra-se a construção de fábricas modernas e empresas agroindustriais, o que abriu possibilidades ao comércio internacional, com a exportação de ouro e petróleo e a importação de bens de consumo e combustíveis. Contudo, é importante ressaltar que, apesar do crescimento da indústria, das atividades manufatureiras e dos setores de transporte, comunicações e serviços públicos (eletricidade, gás e água), a Colômbia manteve a agricultura como uma forte característica econômica, sendo o café responsável por grande parte das exportações ao longo da segunda metade século XX, como se pode evidenciar a seguir:

Quadro 1: Composição do comércio exportador colombiano (\%)

\begin{tabular}{|c|c|c|c|c|c|c|c|c|}
\hline & $1945 / 9$ & $\begin{array}{l}1950 / \\
4\end{array}$ & $\begin{array}{l}1955 / \\
9\end{array}$ & $\begin{array}{l}1960 / \\
4\end{array}$ & $\begin{array}{l}1965 / \\
9\end{array}$ & $\begin{array}{l}1970 / \\
4\end{array}$ & $\begin{array}{l}\text { 1975/ } \\
9\end{array}$ & $1980 / 4$ \\
\hline $\begin{array}{l}\text { Exportações } \\
\text { (composição) }\end{array}$ & & & & & & & & \\
\hline Café & 72.1 & 78.7 & 76.2 & 68.9 & 61.0 & 50.5 & 57.9 & 48.7 \\
\hline Ouro & 5.6 & 2.7 & 2.5 & 2.8 & 1.7 & 1.8 & 2.7 & 6.4 \\
\hline $\begin{array}{l}\text { Petróleo e } \\
\text { óleo }\end{array}$ & 14.6 & 13.6 & 14.3 & 16.1 & 13.5 & 6.9 & 3.9 & 6.6 \\
\hline $\begin{array}{l}\text { Primárias } \\
\text { Outras }\end{array}$ & 7.7 & 5.0 & 7.0 & 9.1 & 15.0 & 19.8 & 16.6 & 19.0 \\
\hline Manufaturas & & & & 3.1 & 8.7 & 21.0 & 18.8 & 19.3 \\
\hline
\end{tabular}

Fonte: Contas Nacionais da Cepal, Banco de La Republica e Dane. Apud Ocampo, p. 253.

Percebe-se que, embora a participação do café colombiano no mercado mundial tenha oscilado entre as décadas de 1940 e 1980, o produto continuou sendo o maior e mais importante componente das exportações do país. Entretanto, ainda é possível visualizar no Quadro 1 que as taxas inconstantes de exportação do país não se restringiram somente ao café, fato que pode ser explicado pelos sucessivos acordos internacionais que se decorreram ao longo dessas décadas e pela lenta diversificação da base exportadora da Colômbia.

\footnotetext{
${ }^{4}$ A participação do setor agropecuário na economia colombiana reduziu de 40\%, em 1949, para 23\%, em 1980, enquanto que as atividades manufatureiras cresceram de 23\%, em 1940, para 40\%, no início da década de 1980.
} 
Segundo Vidigal, a recuperação da economia colombiana na década de 1970 permitiu um incremento das exportações da ordem de 6,3\%, no período entre 1973 e 1980. "Essa tendência sofreu forte inflexão no início da década seguinte, em virtude da queda dos preços do café, dos efeitos da crise mexicana de 1932 e da retração do mercado internacional de capitais" (VIDIGAL, 2004: 176). Além disso, o autor esclarece que:

a modernização da economia da Colômbia foi um caso típico de desenvolvimento periférico, pois aprofundou o caráter primário-exportador do país, promoveu um crescimento industrial limitado em termos tecnológicos e produtivos, e não criou condições para que a Colômbia enfrentasse seus graves problemas sociais. Na década de 1990, houve uma maior concentração de renda: $20 \%$ das famílias mais ricas recebiam $52 \%$ da renda nacional, enquanto $60 \%$ da população encontravam-se abaixo da linha da pobreza. A população que vivia em situação de indigência cresceu, nesses dez anos, de $20 \%$ para $23 \%$ e a terra estava concentrada nas mãos de poucos, com 2\% dos proprietários controlando 53\% da terra (VIDIGAL, 2004:176).

A "modernização" da economia colombiana, relativa e excludente, além de não ter atingido todas as camadas da sociedade, maquiou um processo que estava se alastrando e que se evidenciou a partir da década de 1980. A desigualdade social e a disparidade de renda agravaram e expandiram atividades ilícitas na região, como o tráfico de drogas, que se intensificou com a migração das plantações de maconha e de coca para o território colombiano, causadas, principalmente, por ações repressivas do governo dos Estados Unidos no México, na Jamaica, na Bolívia e no Peru, ao longo das décadas de 1960 a 1990. Entre 1970 e 1980, a Colômbia transformou-se no maior produtor de cocaína do mundo. Foi também nesse mesmo período que o fortalecimento das guerrilhas e o enfraquecimento do poder do Estado aumentaram consideravelmente a violência na região.

Nesse sentido, evidencia-se que a Colômbia vivia em uma enorme contradição, pois apesar de ter se livrado parcialmente das crises das dívidas externas dos países latinoamericanos, era uma das nações com os maiores índices de violência do mundo. De acordo com Vidigal, "a violência vinha minando, lentamente, as instituições governamentais, a estabilidade macroeconômica e a coesão do tecido social" (VIDIGAL, 2004:176). Como exemplo disso, tem-se a cidade colombiana de Medellín, que já no início da década de 1990 registrava 450 homicídios a cada 100 mil habitantes, nível superior ao do país inteiro, que 
registrou no mesmo período, 100 homicídios motivados, entre outras razões, pela violência urbana e pelo narcotráfico ${ }^{5}$.

A situação na qual o país se encontrava também contribuiu para organizações mafiosas. De acordo com Gallego, professor da Universidade Nacional da Colômbia, no caso desse país, as máfias caracterizam-se por ser um modelo de acumulação capitalista criminosa que consegue transitar entre o "legal" e o "ilegal" nos aspectos sociais, econômicos e políticos e por surgirem em um contexto de sociedades pré-modernas e crises estruturais em que as economias ilegais desenvolveram-se mediante o uso da violência como mecanismo coercitivo e de controle (GALLEGO, 2012:143). Nesse sentido, o autor buscou compreender que o aumento do narcotráfico, ligado a uma lógica de mercado, possibilitou o surgimento e a fortificação das máfias colombianas, relacionadas a uma lógica de poder, muito embora elas não se concentrem unicamente no mercado de drogas, podendo envolver outras ramificações da economia capitalista, tais como tráfico de pessoas e de armas.

Bem como é apresentado por Marcelo Santos (SANTOS, 2005:182), a expansão do narcotráfico somada a uma crise institucional e econômica que se alastrava, além de ataques de guerrilhas de esquerda (FARC) contra corporações norte-americanas do petróleo na região, contribuíram sistematicamente para a instalação da política de segurança norte-americana na Colômbia, retirando-lhe a Certificação e até classificando-a como uma "narcodemocracia".

Outro fator importante e que pode ser visto como forte razão para o estabelecimento dessa política foi o crescimento do mercado consumidor interno dos Estados Unidos, que impulsionava - e ainda impulsiona - a oferta de drogas por parte dos países latinoamericanos, em que se destacam Bolívia e Colômbia. Na busca por esse vasto mercado (através da Flórida, Califórnia e Texas), os eixos centro-americanos e caribenhos tornaram-se as principais rotas do tráfico de drogas para os Estados Unidos.

Todos esses motivos contribuíram fortemente para a implementação do Plano Colômbia, em 1999, que se destinou oficialmente ao combate da produção e tráfico de drogas, contudo, também objetivou a desestruturação das guerrilhas de esquerda, como as FARC, contando com o auxílio financeiro e militar dos EUA, na época sob o governo de Bill Clinton, ao governo colombiano, presidido pelo diplomata Andrés Pastrana (1998-2002).

O Plano Colômbia, inicialmente, foi projetado para durar até dezembro de 2005. Foi redigido em uma única versão em inglês e imposto pelo governo norte-americano sem que

\footnotetext{
${ }^{5}$ Dados do Departamento Administrativo Nacional de Estatística (DANE) sobre as mortes para o período de 1980 a 2007 na Colômbia e em Medellín.
} 
houvesse qualquer tipo de consulta ou debate com a sociedade colombiana. É possível visualizar a seguir as seis propostas do documento oficial de Descrição do Suporte dos Estados Unidos para o Plano Colômbia:

1. apoio à expansão das operações antidrogas no sul do país sob a forma de treinamento e equipamento para as Forças Armadas US\$ 416,9 milhões;

2. apoio aos programas de interdição através da modernização do sistema de comunicações dos militares e dos serviços de inteligência - US\$ 378,6 milhões;

3. apoio à Polícia Nacional da Colômbia com treinamento e equipamento - US\$115,6 milhões;

4. apoio ao desenvolvimento econômico e alternativo de atividades que substituam a economia ilícita - US\$ 106 milhões;

5. apoio à reforma do sistema Judiciário e à programas de combate à corrupção, sequestro, lavagem de dinheiro e promoção dos Direitos humanos - US\$ 119 milhões;

6. apoio a outros programas regionais e ao processo de paz - US\$ 183 milhões.

Previa-se o gasto US\$ 7,5 bilhões em recursos externos e internos, para enfrentar a crise colombiana e combater as drogas. Desse valor, os Estados Unidos forneceriam apenas US\$ 1,3 bilhão e o governo colombiano aplicaria US\$ 4 bilhões, sendo que $80 \%$ dos recursos viriam de financiamento externo e $20 \%$ de ajuste fiscal e de impostos sob o controle do FMI, e o restante viria de países europeus e instituições internacionais (SANTOS, 2005:185). O documento destinou suporte financeiro às Forças Militares Colombianas, auxílio ao desenvolvimento econômico e substituição das plantações ilícitas e contemplou propostas sociais e de direitos humanos. Entretanto, o Plano Colômbia materializou-se em verdadeiros ataques abusivos e violentos. Com a erradicação dos cultivos ilegais mediante a fumigação ${ }^{6}$, diversas plantações, principalmente de milho e de mandioca, foram atingidas e totalmente destruídas, arruinando os negócios de pequenos camponeses locais. A alta militarização e o

\footnotetext{
${ }^{6}$ Tratamento químico e tóxico que infectou o solo e colocou em risco a vida de milhares de pessoas.
} 
caráter bélico e repressor constituíram o eixo central do plano, basta analisar a maneira como os recursos financeiros foram distribuídos. Os itens 1, 2 e 3, de caráter essencialmente bélico e militar somam quase US\$ 1 bilhão e os itens 4,5 e 6 , que incluem fatores sociais e econômicos, não chegam nem a metade desse valor.

Na teoria, o Plano Colômbia garantiu a preservação dos direitos humanos, bem como investimentos em prol da paz, contudo, na prática, as operações militares reprimiram protestos sociais, feriram fortemente os direitos humanos e dizimaram plantações inteiras de camponeses cocaleiros, desalojando populações, que tinham a agricultura como única forma de sobrevivência.

O Plano Colômbia tornou-se extremamente contraditório e uma das causas de toda a sua arbitrariedade é o que Bandeira chama de "privatização da guerra na Colômbia". O autor explica que esse processo consistia no envolvimento de corporações militares privadas sem qualquer notificação ou aprovação do Congresso americano, burlando assim a legislação e radicalizando as linhas do conflito. As companhias privadas assumiram o manejo de sistemas de comunicação e radares, fumigação de plantações de coca, investigação de pessoas e armamentos e outras tarefas de inteligência (BANDEIRA, 2005:726).

Dados do Relatório Mundial sobre Drogas, divulgado pela ONU (Organização das Nações Unidas) em 2007, apontaram que o plantio de coca na Colômbia reduziu 9\%, de 86 mil hectares em 2005 para 78 mil hectares em 2006. Essa diminuição foi atribuída, de acordo com o relatório, ao aumento de $24 \%$ da área exposta ao processo de fumigação e ao crescimento de um terço da área envolvida na erradicação manual. Além disso, a produção de cocaína caiu em 5\% e as apreensões desse produto diminuíram em 27\% no ano de 2005. Embora os resultados pareçam relevantes, é importante considerar que foram obtidos mediante uma série de intervenções arbitrárias por parte dos Estados Unidos. Além disso, segundo a ONU, o índice de replantio de coca chegou a $40 \%$ da área erradicada e a migração dos cultivos para outros países da região continuam ocorrendo. É importante fazer mais uma consideração: o relatório ainda revelou que apesar da diminuição das plantações de coca na Colômbia, "o país continua sendo o maior cultivador da planta e produtor global de cocaína, sendo responsável por 62\% da droga encontrada no planeta" (SANTOS, 2007:197).

Como se pode observar, a estratégia de "guerra de baixa intensidade" posta em prática pelos Estados Unidos com uma série de intervenções de alta intensidade, não foi e continua não sendo a melhor opção para o combate ao tráfico de drogas, pois o narcotráfico, na 
verdade, está relacionado a uma série de problemáticas sociais que são muito maiores que as atividades consideradas ilícitas.

Narcotráfico, desigualdade social, pobreza e violência

A desigualdade social configura uma das fortes razões pelas quais se formam grupos ligados às atividades criminosas, entre elas o narcotráfico, principalmente em populações mais pobres, nas favelas e periferias, por falta de oportunidades de vida, sem acesso a educação, trabalho, moradia e segurança.

O estudo realizado pela UNESCO no ano de 2002, sobre juventude, violência e vulnerabilidade social na América Latina, sustenta que:

a violência sofrida pelos jovens possui fortes vínculos com a vulnerabilidade social em que se encontra a juventude nos países latino-americanos, dificultando, por conseguinte, o seu acesso às estruturas de oportunidades disponíveis nos campos da saúde, educação, trabalho, lazer e cultura. O contingente de jovens em situação de vulnerabilidade, aliada às turbulentas condições socioeconômicas de muitos países latino-americanos ocasiona uma grande tensão entre os jovens que agrava diretamente os processos de integração social e, em algumas situações, fomenta o aumento da violência e da criminalidade (UNESCO, 2002:9).

Desde a década de 1990, a agenda social na América Latina tem sido definida pela renovada preocupação sobre a prevalência da pobreza e a manutenção e aparição de novas desigualdades. Marcello Baquero afirma que as evidências que respaldam essa preocupação são o crescimento da pobreza em termos de números de pessoas afetadas, a estagnação ou aumento do desemprego e o aumento da desigualdade de renda (BAQUERO, 2007:37). O autor ainda expõe que a persistência de desigualdades e de pobreza são características perversas da região latino-americana, incidindo negativamente em todos os processos de desenvolvimento. Para o autor, "as desigualdades extremas de oportunidades e possibilidades da vida afetam diretamente as capacidades do ser humano" (BAQUERO, 2007:28).

Angelina Peralva acredita que, no Brasil, por exemplo, existe um paradoxo ligado ao aumento de "crimes de sangue" entre 1980 e 1997. Segundo a autora, esse período caracterizou-se pelo investimento na construção da democracia pós-ditadura militar, em contrapartida ao crescimento do acesso a armas de fogo e a presença do narcotráfico, principalmente em zonas de pobreza das áreas urbanas (PERALVA, 2000). Paulo Sérgio 
Pinheiro corrobora com a ideia de "paradoxo brasileiro", mas no sentido de coexistirem uma definição estrita das garantias constitucionais e uma cidadania fraca. De acordo com o autor, o Brasil oferece o paradoxo de estar ao mesmo tempo no que poderia ser o melhor e o pior país, pois uma das dez maiores economias mundiais convive com uma das piores distribuições de renda em todo o mundo (PINHEIRO, 1996:22-24).

No caso da Colômbia, essa desigualdade pode ser notada pelas condições econômicas da agricultura andina, com o cultivo da folha de coca, movimentado por grupos economicamente instáveis e socialmente desiguais, em que se destacam os camponeses cocaleiros, nas regiões de Nariño, Caquetá e Miraflores, por exemplo. Muitos veem a produção e o comércio de coca como única forma de trabalho e sobrevivência, tanto é que essa atividade contribui para o mercado de turismo em diversos países, tais como na Bolívia e no Peru ${ }^{7}$. Apesar de existir uma legislação rígida e específica de controle ao seu cultivo, que proíbe, inclusive, o uso indevido e o tráfico ilícito de entorpecentes, a coca é uma tradição em várias regiões da América Latina, é reconhecida como "planta sagrada" de estudo e conhecimento por diversas comunidades indígenas, e no seu estado natural, além de ser utilizada em rituais religiosos, também é considerada alimento e medicamento. Por mais que existam diferenças entre a ancestralidade da planta e o narcotráfico, as plantações foram alvos do Plano Colômbia por contribuírem na produção de cocaína. Ademais, na Colômbia ainda existe outro agravante que motiva as plantações de coca e o narcotráfico: a presença maçante de grupos guerrilheiros de esquerda que também dependem financeiramente do tráfico de drogas.

A desigualdade social é responsável e constitui uma das bases da pirâmide da atividade do narcotráfico, e caso se queira combatê-la é preciso olhar primeiro para a base dessa pirâmide, mas não na forma de "guerra de baixa intensidade", como proposta pelos Estados Unidos, pois além de ferir os direitos humanos, não resolve o problema, pelo contrário, o agrava.

O combate à desigualdade social, além de não ser um problema inferior ao combate ao narcotráfico, não é uma tarefa fácil, no entanto, alguns caminhos podem ser trilhados. No Brasil, por exemplo, foram criados pelo governo federal, programas sociais de combate à pobreza, como o Fome Zero, que tirou o país do mapa da fome, e o Bolsa Família, que apesar

\footnotetext{
${ }^{7}$ Os turistas, ao visitarem Machu Picchu, em Cuzco, no Peru, tomam o chá ou mastigam a folha de coca para aliviar a sensação de desconforto causada pelo excesso de altitude.
} 
de despertar críticas de setores mais conservadores, auxilia, embora com uma mínima quantidade, milhares de famílias em todo o Brasil. Além disso, as políticas afirmativas também são uma alternativa, como as cotas sociais, para o ingresso de estudantes de baixa renda em instituições públicas e privadas de ensino superior.

Outros países da América Latina têm seguido o exemplo do Brasil, com a criação de políticas sociais e econômicas, é o caso do Plano para a Erradicação da Extrema Pobreza, na Bolívia. Recentemente, em fevereiro de 2016, o atual presidente do país, Evo Morales, esteve no Brasil para discutir e se unir no combate à fome, à redução da pobreza e à desigualdade social na América Latina.

Além da Bolívia, desde o ano de 2014, o Brasil tem auxiliado a Colômbia por meio de políticas públicas e sociais, é o caso do Programa de Aquisição de Alimentos da Colômbia, que tem como objetivo o fortalecimento da agricultura familiar, por meio de programas de ampliação e qualificação da produção rural. É interessante pensar, no caso específico da Colômbia, em políticas de gestão territorial aliadas ao desenvolvimento e à manutenção das plantações que foram parcial ou totalmente destruídas pela fumigação adotada no Plano Colômbia, visto que esse processo afetou também outras plantações, degradando o solo e dificultando a substituição desses cultivos.

Segundo o relatório Estado de las ciudades de América Latina y el Caribe, publicado em 2012 pelo Programa das Nações Unidas para os Assentamentos Humanos (ONU-Habitat), os países da América Latina, vistos em seu conjunto, são e se mantiveram como os mais desiguais do planeta, sendo que as cidades latino-americanas são duais, divididas e segregadas, do ponto de vista espacial e social. Existem até barreiras erguidas - os chamados "muros da vergonha" - que separam pobres e ricos. Em Lima, no Peru, um muro de $10 \mathrm{~km}$ de comprimento divide uma das zonas mais abastadas de uma das zonas mais marginalizadas da cidade $^{8}$.

Ainda de acordo com o relatório, a Colômbia é o $3^{\circ}$ país mais desigual da América Latina, seguido por Brasil, República Dominicana e Bolívia, a Guatemala ocupa o $1^{\circ}$ lugar e Honduras, o $2^{\circ}$. Também são apresentados dados das taxas de pobreza de países como a Argentina, Chile e Uruguai, que possuem uma incidência de pobreza nacional baixa (inferior a $12 \%$ da população). Mais da metade dos habitantes da Bolívia, Guatemala e Paraguai é pobre, na Nicarágua e em Honduras essa taxa supera os $60 \%$. Com relação à moradia em áreas precárias, tais como em invasões e assentamentos irregulares, o caso mais dramático e

\footnotetext{
${ }^{8}$ Assistir vídeo: <https://www.youtube.com/watch?v=Q9oUv_SBhv0> Acesso em: 31 Out. 2016.
} 
preocupante é o do Haiti, onde a quantidade de pessoas nessa situação representa mais de $70 \%$ da população. A situação sem dúvida agravou-se ainda mais depois da passagem do furação Matthew, em outubro de 2016. A Bolívia aparece em $3^{\circ}$ lugar e a Colômbia tem mais de $20 \%$ da população vivendo em condições extremamente precárias de moradia.

Segundo análise do Centro de Informação das Nações Unidas no Rio de Janeiro (UNIC-Rio), todos esses dados mostram que além da pobreza, a América Latina sofre de um problema de desigualdade grave e persistente. A disparidade de renda é extremamente elevada, há um déficit considerável de emprego e uma abundante informalidade trabalhista, que se concentram nos jovens e nas mulheres. A desigualdade nas cidades manifesta-se social e espacialmente, pois as oportunidades para o desenvolvimento econômico e social que oferece a urbanização não chegam a todos os segmentos sociais.

É preciso tratar esse problema de um panorama menos amplo e mais específico, embora os países da América Latina tenham em comum a desigualdade social, cada região vive uma realidade e enfrenta os problemas de maneiras diferentes, até porque estão inseridos em contextos políticos, econômicos e financeiros distintos. Trabalhar o problema da desigualdade social dos países latino-americanos de uma maneira mais específica e menos genérica é de fundamental importância para entender as causas, as consequências e as resoluções do narcotráfico em cada região da América Latina.

\section{Conclusão}

Percebe-se com o Plano Colômbia até onde um país como os Estados Unidos pode ir para proteger seus interesses e combater os problemas externos considerados ameaçadores à sua integridade política, econômica e militar. A estratégia norte-americana de "guerra de baixa intensidade", além de contraditória, foi altamente intervencionista, desumana e violenta. Preocupou-se mais com fatores políticos e financeiros em detrimento do fator social. $\mathrm{Na}$ prática, não se importou com a condição de milhares de pessoas e nem com os direitos humanos. Descartou os problemas da sociedade latino-americana como um todo e considerou o narcotráfico como algo dissociado da desigualdade social.

A política de segurança norte-americana parece ter desconsiderado a enorme demanda de seu próprio mercado consumidor interno, que estimula cada vez mais a oferta de drogas dos países latino-americanos. Quis combater o problema em sua raiz, mas ignorou a sua própria população. Desconsiderou também o fato de que a atividade do narcotráfico é mais 
um ramo da economia capitalista mundial, altamente defendida pelos EUA na Guerra Fria e posta em prática diariamente em seu âmbito interno e externo. Ignorou o fato de que não é só a América Latina que precisa de atenção e tratamento, mas os EUA também. A política de segurança norte-americana funcionou como um rigoroso instrumento de controle social sobre determinados segmentos da população norte-americana tais como negros, hispânicos e pobres, e na América Latina, apesar da justificativa de objetivos geopolíticos e geoeconômicos, serviu com um instrumento repressivo para que as elites aliadas reprimissem fortemente segmentos sociais desfavorecidos.

As políticas de drogas existem, mas ainda são caracterizadas pela punição e repressão social em detrimento de fatores como investimentos em educação e saúde pública. Nesse sentido, os grupos com maior vulnerabilidade socioeconômica ainda são os principais atingidos: pessoas negras, pobres e periféricas.

A guerra às drogas é algo muito aquém do que se precisa. Além de ser uma guerra perdida, que só gera mais violência, não resolve o problema de milhares de pessoas em situações precárias de vida, pelo contrário, alimenta ainda mais a exclusão, a vulnerabilidade social e as atividades criminosas. O caso da Colômbia sugere que é a desigualdade social que se deve combater e são em políticas públicas que se deve pensar. Essa deve ser uma preocupação geral, não só da Colômbia, mas de todos os governos da América Latina.

\section{Referências bibliográficas}

ABRAMOVAY, Miriam. Juventude, violência e vulnerabilidade social na América Latina: desafios para políticas públicas. Brasília: UNESCO, BID, 2002. Disponível em: http://unesdoc.unesco.org/images/0012/001271/127138por.pdf Acesso em: 29. Out. 2016.

AZAMBUJA, Carlos. Os conflitos de baixa intensidade. Disponível em: http://www.alertatotal.net/2015/02/osconflitos-de-baixa-intensidade.htmlAcesso em: 13 Jun. 2016.

BANDEIRA, Luiz Alberto Moniz. Formação do império americano: da guerra contra a Espanha à guerra no Iraque. Rio de Janeiro: Civilização Brasileira, 2005.

BAQUERO, Marcello. Democracia e desigualdades na América Latina: novas perspectivas. Porto Alegre: Editora da UFRGS, 2007.

BARROSO, Luís Fernando Machado. Da Guerra: lições de conflitos armados. Revista Militar no 2484. Lisboa, 2009. Disponível em: https://www.revistamilitar.pt/artigo.php?art id=365 Acesso em: 13 Jun. 2016.

FRANCO, Saúl; GALLO, Gloria Patricia; GARCIA, Gloria Milena; GARCÍA, Héctor Iván; MERCEDES, Clara; ROZO, Patricia; VERA, Claudia Yaneth. Mortalidad por homicidio en Medellín, 1980-2007. Disponível em: http://www.scielo.br/pdf/csc/v17n12/06.pdf Acesso em: 18 Mar. 2017. 
GALLEGO, Carlos Medina. Mafia y narcotráfico en Colombia: elementos para un estudio comparado. In: El prisma de las seguridades en América Latina. Escenarios regionales y locales. Buenos Aires, 2012. Disponível em: http://bibliotecavirtual.clacso.org.ar/clacso/gt/20120412011532/prisma-6.pdf Acesso em: 18 Mar. 2017.

HERZ, Monica. Política de segurança dos EUA para a América Latina após o final da Guerra Fria. Revista Estudos Avançados vol. 16, $\mathrm{n}^{\circ}$ 46. São Paulo, 2002. Disponível em: http://www.scielo.br/scielo.php?script=sci_arttext\&pid=S0103-40142002000300007 Acesso em 12 Jun. 2016.

PERALVA, Angelina. Violência e democracia: o paradoxo brasileiro. São Paulo: Paz e Terra, 2000.

PINHEIRO, Paulo Sérgio. Prefácio: o passado não está morto, nem passado é ainda. In: DIMENSTEIN, Gilberto. Democracia em pedaços: direitos humanos no Brasil. São Paulo: Cia das Letras, 1996.

SANTOS, Marcelo. A política de segurança dos EUA para a América Latina no pós-Guerra Fria.In: SANTOS, Marcelo. O poder norte-americano e a América Latina no pós-guerra fria. São Paulo: Annablume; Fapesp, 2007.

, Marcelo. A política dos Estados Unidos de combate ao narcotráfico e o Plano Colômbia (19982005).Estudos de Sociologia, v.12, $\mathrm{n}^{\mathrm{o}}$ 22. Araraquara, 2006. Disponível em: http://seer.fclar.unesp.br/estudos/article/viewFile/354/218 Acesso em: 14 Jun. 2016.

TENA, BelenBoville Luca de. La guerra de la cocaína: drogas, geopolítica y medio ambiente. Madrid: Editorial Debate, 2000.

UNIC-Rio de Janeiro. ONU lança relatório sobre cidades latino-americanas. Disponível em: <http://unicrio.org.br/>. Acesso em: 14 Jun. 2016.

UNITED NATIONS. Conventionon Psychotropic Substances, 1971. Disponível em: 〈http://www.unodc.org/pdf/convention_1971_en.pdf >. Acesso em: 14 Jun. 2016. . Description of the support of the United States on the Plan Colombia. Disponível em: <http://www.state.gov/>. Acesso em: 14 Jun. 2016. . World Drug Report, 2007. Disponível em: <http://www.unodc.org/lpo-brazil/pt/drogas/relatoriomundial-sobre-drogas.html >. Acesso em: 14 Jun. 2016.

Estado de las ciudades de América Latina y el Caribe. Programa das Nações Unidas para os Assentamentos Humanos (ONU-Habitat), 2012. Disponível em: <http://es.unhabitat.org/>. Acesso em: 14 Jun. 2016.

VIDIGAL, Carlos Eduardo. Colômbia: Economia nacional e suas relações com a economia regional $e$ internacional. In: ARAUJO, Heloisa Vilhena de. Org. Os países da Comunidade Andina, volume 1. Brasília: Fundação Alexandre Gusmão (FUNAG): Instituto de Pesquisa de Relações Internacionais, 2004. p. 171-193. 